\title{
GRUPO DE ARTISTAS DE VANGUARDIA: UN ITINERARIO
}

\author{
VANGUARD GROUP OF ARTISTS: A JOURNEY ${ }^{1}$
}

Páginas 45-60

\section{Luciana Fiori2 Virginia Inés Vega ${ }^{3}$ ARGENTINA}

Palabras Claves: vanguardia, revolución, ética, estética, política.

Keywords: vanguard, revolution, ethics, aesthetics, politics

\section{Resumen}

El presente artículo aborda el camino recorrido por el Grupo de Artistas de Vanguardia desde su conformación en el año 1966 hasta su disolución con la obra "Tucumán Arde" en 1968.

Este recorrido está atravesado por el proceso de radicalización política y estética que van asumiendo los protagonistas. El compromiso tomado por los artistas los aleja de las instituciones modernizadoras del campo artístico tradicional y los conduce al trabajo conjunto con la central obrera más radicalizada del momento: la CGT de los Argentinos. Vemos así que la muestra "Tucumán Arde" es producto del cruce de las vanguardias estéticas y políticas.

\section{Abstract}

This paper approaches the path followed by the Vanguard Group of Artists since its origin in 1966 until its end with the project "Tucumán Arde" (Tucumán is Burning) in 1968.

This journey is crossed by the process of political radicalization and aesthetics assumed by the protagonists. The artists' commitment drives them away from modernizing institutions of the traditional artistic field and guides them to group work with the most radical labor union at the time: the Argentinian CGT. Thus, we see that "Tucumán Arde" sample is the result of the intersection of aesthetic and political vanguards.
1 Traducción de Blanca Stella Giraldo. Revisión Centro de Traducción del Instituto de Idiomas UAM.

2 Luciana Fiori, DNI $\mathrm{N}^{\circ}$ 28.818.594. Nació el 19 de marzo de 1981 en al ciudad de Rosario, provincia de Santa Fe, Argentina. En el año 2009 se graduó de Profesora de Historia en la Facultad de Humanidades y Artes de la Universidad Nacional de Rosario.

3 Virginia Inés Vega, DNI $\mathrm{N}^{\circ}$ 28.035.394. Nació el 24 de marzo de 1980 en al ciudad de Rosario, provincia de Santa $\mathrm{Fe}$, Argentina. En el año 2009 se graduó de Profesora de Historia en la Facultad de Humanidades y Artes de la Universidad Nacional de Rosario.

Fecha recibido: 14-05-10

Fecha aprobado: 15-07-10

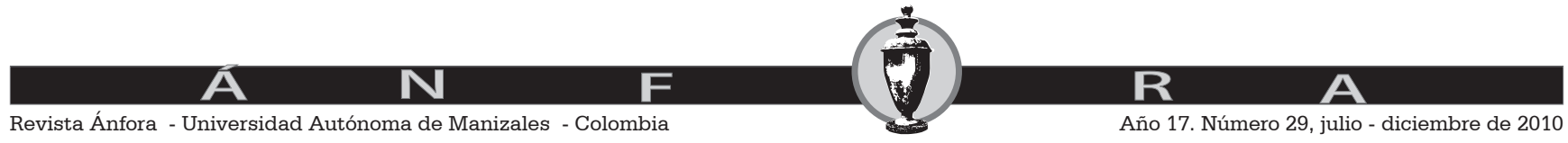




\section{INTRODUCCIÓN}

“TUCUMÁN ARDE" fue una obra colectiva que en el año 1968 realizó un grupo de artistas argentinos provenientes de las ciudades de Rosario, Buenos Aires y Santa Fe. La misma se inscribió en una zona de múltiples fracturas (LONGONI y MESTMAN, 2000). Por una parte, las provocadas por las profundas escisiones del campo político, social y económico, producidas por la inviabilidad de un modelo de país. Por otra, aquellas que marcaron los sucesivos quiebres que se produjeron en la avanzada artística de la vanguardia, generados por el conjunto de acciones encadenadas que, durante 1968, hicieron del campo artístico y de sus instituciones un virtual campo de batalla.

Sin negar que el '66 haya significado también una fisura importante para el campo artístico, un "parteaguas" en el plano simbólico, como lo califica Terán (1991), 1968 permite visualizar con claridad un proceso de corrimiento del compromiso del artista con el arte al compromiso con la política. En tanto se sienten capaces de poner en crisis los valores vigentes en la sociedad a la que pertenecen y de contribuir a fundar un orden alternativo, y en tanto demuestran una voluntad de intervención en la escena pública a fin de incidir en el orden establecido, los artistas se reconocen como intelectuales y en ese reconocimiento incluyen también sus prácticas estéticas específicas. El paso de ser un artista de vanguardia a artista/intelectual comprometido, es un proceso que comienza a mediados de la década y se consuma en 1968 de un modo acelerado y radical (GIUNTA, 2001).

Nosotras volcamos nuestra mirada sobre el itinerario recorrido por los artistas del grupo de vanguardia desde su conformación hasta su culminación con la obra Tucumán Arde. Porque consideramos que los interrogantes que esta obra planteó respecto de la concepción del rol del arte, del artista y del público no han perdido vigencia y a su vez condensan un clima de época. En otras palabras, la validez historiográfica del estudio de una obra de arte reside en que ésta nos permite conocer en profundidad la atmósfera de una época determinada, el conjunto de pensamientos, ideas, creencias, costumbres, sentimientos, estrategias de lucha y de resistencia propias de un momento histórico determinado. "La obra de arte abre un mundo; nos introduce en la complejidad de un momento de la historia" (OLIVERAS, 2006, p. 48).

A comienzos de 1968 era evidente que si la vanguardia quería seguir siendo un elemento perturbador, si pretendía trastornar el orden de las cosas, no podía ya actuar dentro del marco de las instituciones. La propuesta del Grupo de Artistas de Vanguardia, que ejecutó la muestra, era realizar un arte colectivo que actuara directamente sobre la realidad, y que denunciara las situaciones políticas, sociales y económicas que aquejaban al país.

En este sentido, un lugar propicio para comenzar parecía ofrecerlo la candente crisis que afectaba a la provincia de Tucumán. Sus problemas fueron leídos como un paradigma del desparpajo con el que desde el gobierno nacional se instrumentaban proyectos tendientes a favorecer a los grandes monopolios. El

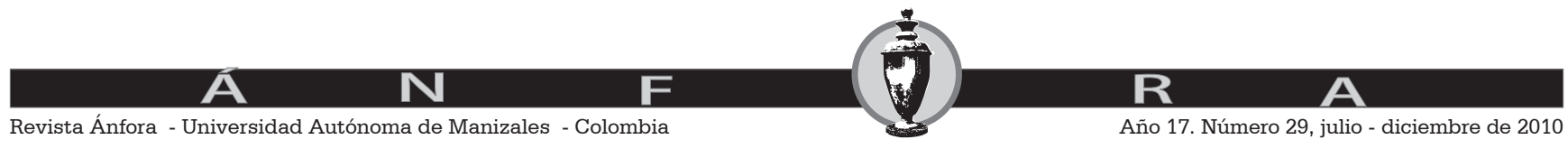


gobierno publicitaba el "Operativo Tucumán" como un proyecto de acelerada industrialización, cuando en realidad lo que se buscaba era la sustitución de la burguesía nacional por el capital norteAméricano. El objetivo central del proyecto de los artistas era denunciar la distancia entre la realidad y la publicidad y para esto concibieron su acción como un instrumento de contrainformación.

Los contenidos del arte tenían que ser claros y definidos. Lo que urgía no era el reemplazo de un estilo por otro sino cuestionar la organización del campo artístico, sus instituciones y las estrategias simbólicas de las clases dominantes. Desde ahora, según afirmaban los artistas en el manifiesto con el que se presentaban, la creación estética se postulaba como una acción colectiva y violenta.

Este nuevo proceso incluye las críticas a las instituciones, el acercamiento de los intelectuales a los obreros, la identificación del arte y la vida. Surge así un arte político que critica no sólo al arte experimental sino también al "arte burgués." El "acabado", el "buen gusto", que caracterizaban lo que los artistas definían como "cultura mermelada" eran los rasgos del arte burgués. Contra estas tendencias establecidas se revelaron los artistas. Pretendían una vanguardia en términos de experimentación y renovación del lenguaje, como un atentado al gusto establecido.

Los artistas se constituyeron en actores activos dispuestos a modificar el contexto. La intención de realizar un arte político surgió de una primera instancia en la cual se intentó desmuseificar la experiencia estética, como resultado de este proceso se llegó a romper el mismo concepto de lo estético. Se rompía con el espacio básico del museo para extenderse hacia los medios masivos de comunicación en la búsqueda por alcanzar un nuevo público.

El proyecto de la vanguardia artística de los años sesenta debe entenderse en el marco del intenso proceso de modernización cultural que caracterizó el momento "desarrollista". Para un país que expandía tan intensamente su economía era necesaria también la transformación y el desarrollo en el terreno de la cultura. Tal proyecto contó con fuertes gestores en la pujante burguesía industrial, como, por ejemplo, el Instituto Torcuato Di Tella, y en sectores de la intelectualidad que actuaron como oportunos aliados que les permitieron sacar el programa de crecimiento y desarrollo de los circuitos exclusivamente económicos.

El concepto de vanguardia artística es muy dinámico y será redefinido a lo largo del período estudiado. Si a comienzos de la década la problemática dominante de los sectores de vanguardia, pasaba por la actitud experimental dirigida a la transformación de las estructuras formales, después de 1965 será cada vez más difícil pensar el arte y la vanguardia al margen de las preocupaciones y posicionamientos políticos. En este reposicionamiento el arte fue, cada vez más, representación y gesto, y también un problema en torno a la ética y al poder. Una dinámica en la que el relato del artista individual fue sustituido por el artista social (el abandono de los talleres y las galerías por la calle) y en el que la voluntad diferenciadora del género y el estilo fue suplantado por la opción, primero y el imperativo, poco después, de la política.

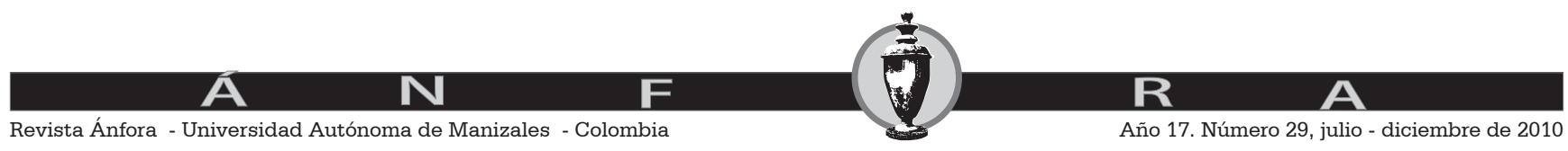


La muestra "TUCUMÁN ARDE" fue el punto culminante del camino de rupturas que experimentó la vanguardia artística durante las Experiencias '68. Ruptura que se manifiesta en el abandono de las instituciones modernizadoras, el Di Tella, por instituciones ajenas al campo artístico como la CGT de los Argentinos ${ }^{4}$.

I

El hecho de que el '66 sea el año de la consagración del Pop en el Di Tella, de mayor realización de happenings, de emergencia del arte de los medios y de planteos de índole conceptual, da cuenta de una dinámica marcada por una renovación vertiginosa.

Para ese año en Rosario, el Grupo de Arte de Vanguardia ya está constituido como sujeto colectivo y protagoniza hechos que le dan visibilidad en el medio cultural local. La muestra realizada en la Plaza 25 de Mayo, titulada "Exposición de pinturas y collages" no sólo sorprendió a los transeúntes desprevenidos sino que alentó polémicas y obligó a tomas de posición. Ésta significó el punto de partida del camino de rupturas que inició el Grupo de Arte de Vanguardia y si bien como dice Guillermo Fantoni (1989-1990):

"aunque la muestra no fue propuesta inicialmente como una ruptura, implicó un conjunto de planteos a través de los cuales estos vanguardistas van a comenzar a congregarse, así como también a recuperar algo que la generación de sus maestros había perdido: la capacidad de confrontación".

En septiembre de 1966, el Grupo de Arte de Vanguardia publicó su primer volante-manifiesto que se tituló "A propósito de la cultura mermelada", denominando así a la "empalagosa" cultura oficial, a la cual ellos consideraban obstáculo y freno de la labor creadora. En lo que a su labor respecta, los artistas se manifiestan en contra de obras falsamente vanguardistas que bajo una apariencia moderna representan la más recalcitrante actitud académica. Criticaban que estas expresiones artísticas se quedaban en el simple juego decorativo de la superficie de la obra; obras que, por no preocupar a nadie, encuentran un buen mercado. En este manifiesto los plásticos reprochan a la "crítica mermelada" que nunca leen una obra, ni esperan a que ésta les proponga su sistema, para luego emitir su juicio; sino que pretenden encasillarla en sus rancios esquemas.

En contraposición a la cultura oficial/ cultura mermelada, ellos se declaran a favor de una pintura creadora y revolucionaria, que aporte siempre nuevas posibilidades de conocimiento y de emociones al observador; una pintura de estudio, de investigación, que sintetice de manera expresiva las posibilidades intelectuales de quienes las hacen. Interpretamos este manifiesto como
4 La CGT de los Argentinos surgió como una respuesta combativa a las variantes de adaptación al régimen generadas por las conducciones burocratizadas del sindicalismo peronista, nucleadas en las 62 Organizaciones con la hegemonía de la Unión Obrera Metalúrgica de Augusto Timoteo Vandor. Ver JAMES, D. Resistencia e integración. El peronismo y la clase trabajadora argentina, 19461976. Siglo XXI Editores, Bs. As. 2006 .Cap. 4 "La era Vandor, 1962-66".

5 Fuente consultada en el Archivo personal de la artista plástica Graciela Carnevale.

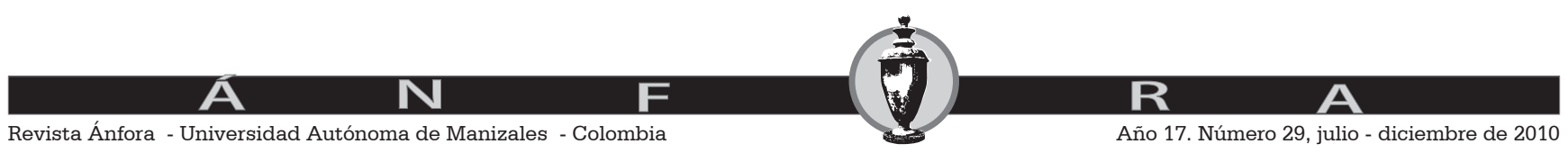


una toma de posición explícita de los artistas contra las formas y prácticas oficializadas del arte, y vemos que en él se expresa una mayor consolidación y autoconciencia del grupo y de su ubicación en el campo.

El año 1966 es también el momento en que se inician los contactos del grupo rosarino con la vanguardia porteña: en abril los rosarinos realizan una muestra en la galería Pro-Art y la participación de artistas rosarinos en el Homenaje al Viet-Nam en octubre de ese mismo año, entre otras actividades realizadas en la ciudad de Buenos Aires. Para 1967 el grupo rosarino se consolida, alentado no sólo por la dinámica interna, sino también por el espaldarazo que le proporcionan los críticos y gestores Jorge Romero Brest y Jorge Glusberg, desde Buenos Aires. Así, 1968 los encontró instalados como uno de los grupos más dinámicos en la escena artística nacional.

\section{II}

En el año 1968 hubo una fuerte reacción contestataria contra la política de censura del gobierno. Ese será un año de quiebres y fuertes cambios para el grupo de jóvenes artistas de Rosario. Los planteos que comenzará a proponer este grupo de artistas cuestionaban no sólo los fundamentos del arte sino también las bases políticas y sociales, y buscaban evitar ser incorporados e inutilizados por la burguesía. En palabras de los propios artistas, lo que buscaban era la creación de "estrategias culturales alternativas"6.

Ante un panorama de fuerte intervención estatal que se dirigía a todos los ámbitos de la vida, surgieron voces de descontento. En nuestra región el clima de contestación social hundió sus raíces en el campo intelectual y cultural de la época, hubo una intensa y masiva participación de los jóvenes y de los trabajadores, quienes a través de sus organizaciones ganaron protagonismo en la escena pública.

En las fuentes analizadas vemos como, hacia 1968 se profundiza la preocupación de los artistas por la inserción del arte de vanguardia en el medio social. Iniciaron así una serie de discusiones centradas en las posibilidades de crear un fenómeno cultural que cumpliera verdaderamente un papel revulsivo y disolvente de los principios éticos y estéticos de la sociedad, asumiendo de este modo su rol de vanguardistas. Así, comenzaron a ensayar algunas obras que tratan de poner en práctica esos principios.

El 30 de abril de 1968, la inauguración del Premio ver y Estimar fue interrumpida abruptamente. Eduardo Ruano, uno de los artistas convocados a participar del mismo, entró en la sala del Museo de Arte Moderno junto a otros artistas al grito de "iFuera yanquis de Vietnam!". Corearon también otras consignas antiimperialistas y procedieron a la destrucción de la imagen de Kennedy montada por el propio artista a modo de atentado.

Este hecho fue muy significativo ya que inauguró una modalidad de intervención artístico-política de la vanguardia. Esto puede considerarse como el pasaje de la obra-objeto a la obra-acción que, a diferencia de los happenings y ambientacio-
6 Fuente consultada en el Archivo personal de la artista plástica Graciela Carnevale..

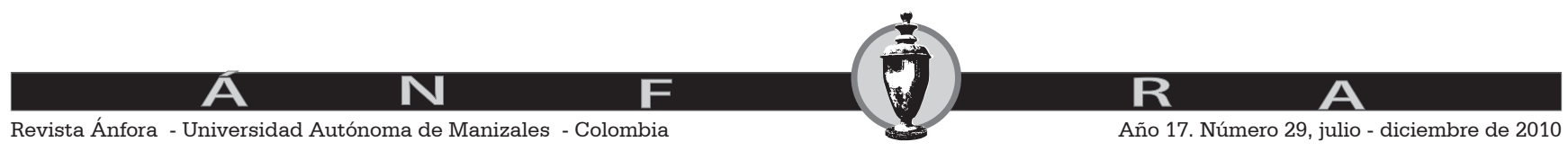


nes anteriores, está acompañado por otro corrimiento. Se deja de lado la representación de la violencia política, para pasar a realizar actos -artísticos- de violencia -política- (LONGONI y MESTMAN, 2000). En estas acciones los artistas se apropian (como materiales estéticos) de recursos, modalidades y procedimientos propios del ámbito de la política. Ellos mismos definen la intervención de Ver y Estimar como un "atentado", que se dirige al mismo tiempo contra dos frentes: la política exterior norteAméricana y la "institución arte".

La acción de Ruano pone de manifiesto la incipiente ruptura con las instituciones del circuito modernizador, los premios, museos y galerías que venían acogiendo a la vanguardia, aunque este quiebre todavía se instale en el interior de las mismas. Es por eso que este proceso de ruptura es todavía contradictorio. Si bien, en las Experiencias 1968 del Di Tella, estalla a todas luces el conflicto entre gran parte de la vanguardia y la institución, todavía el premio Ver y Estimar es visualizado como un lugar al que resultaba legítimo presentarse desde la perspectiva de los artistas experimentales.

A pesar de que "el atentado" no fue la primera manifestación política en las artes plásticas de los años '60, su carácter era sin duda inaugural. Esto se debe a que inició una seguidilla de acciones artístico-políticas llevadas a cabo colectivamente por un núcleo de la vanguardia artística argentina de los años '60, que postuló una forma excepcional de cruce entre arte y política. Característico de un clima de época que se condensa y se simboliza en las revueltas estudiantiles y populares que conmovieron en mayo a Francia y entre agosto y octubre a México y en cuyo seno se originaron radicales corrientes de pensamiento y acción.

Interpretamos a este itinerario como una serie de escenas que muestran la crisis y la ruptura de los plásticos con los ámbitos artísticos en los que venían interviniendo hasta entonces, y muestran paralelamente, la progresiva disolución de las fronteras entre acción artística y acción política.

Las "Experiencias" anualmente convocadas por el Instituto Di Tella, eran el mayor acontecimiento de la vanguardia. Pero para el '68 representaron sobre todo, la radicalización política de muchos artistas que se manifestó tanto en sus planteos artísticos como en los modos de intervención que se generaron a partir de la censura. _Durante la muestra se desencadena la ruptura de la vanguardia con la institución más importante del circuito que la albergaba.

En la carta abierta enviada por el pintor Pablo Suárez a su Director Jorge Romero Brest, el artista destaca su incapacidad moral para participar dentro de una institución a la cual considera cómplice de la censura oficial.

El artista Eduardo Ruano, a pesar de no haber sido invitado, decide participar de hecho en las Experiencias, y elige una m odalidad de participación similar a la de Pablo Suárez. El día de la inauguración, cuando en el Instituto estaban las autoridades y una representación del Consejo Internacional del Museo de Arte Moderno de Nueva York, Ruano realiza un nuevo acto relámpago distribuyendo un panfleto en contra de la censura oficial sobre las

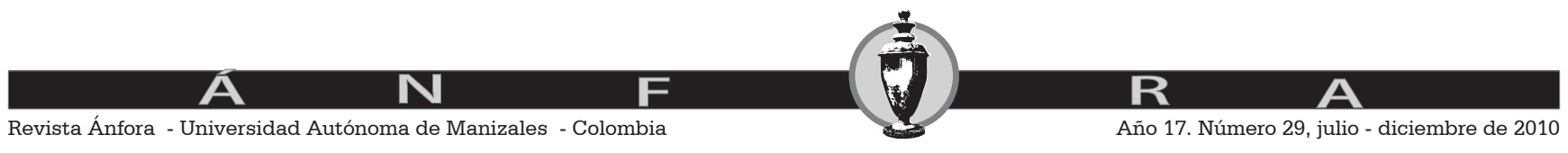


obras que utilizan temas políticos como material estético. Suárez y Ruano se ubican de este modo en los márgenes de la institución. Intervienen con un formato, el volante o panfleto, el cual tiene un doble carácter: como renuncia a participar y como obra de arte participante en la muestra.

Todavíadentrodelainstitución, RobertoJacobyoptóporinscribirsucríticaalaculturaoficialenelinteriordelCentroArtísticodeVanguardia,ydesplegóun muralen elcual manifiesta su concepción del artey del artista, en clara contraposición ala institución oficial. Haceénfasis en quela vanguardia no puede dejar de afirmarla historia, de afirmar la violencia de la lucha por la creación de un mundo nuevo.

Este clima de conflictividad con las instituciones y de efervescencia política estalla el 23 de mayo con la clausura de la obra de Plate conocida como "El Baño". Se trataba del simulacro de un baño público donde los asistentes entraban enfrentándose "a solas" con paredes blancas, en cubículos vacíos, sin artefactos sanitarios. El autor buscaba que el público percibiera un resguardo de su intimidad suficiente como para producir "actos de descarga a nivel emocional". Por supuesto, los graffitis que realizaban los espectadores expresaban el profundo descontento hacia el gobierno dictatorial del General Juan Carlos Onganía.

En solidaridad con Plate y en repudio a la censura, los artistas retiraron sus obras del Di Tella en son de protesta. Las destruyeron y arrojaron sus restos a la calle provocando el caos. El tumulto terminó con la intervención policial y el arresto de varios artistas. Ante este suceso los artistas emitieron una declaración seguida por 64 firmas, que incluían, además de las de los participantes en las Experiencias '68, las de otros artistas e intelectuales que se solidarizaron con ellos (entre otras, es destacable la firma de Rodolfo Walsh, que ya dirigía el Semanario CGT y poco después actuaría como nexo entre artistas y sindicalistas). Este documento, si bien hacía eje en un fuerte cuestionamiento a la censura, también incorporaba una denuncia más amplia de la represión política ejercida por el gobierno hacia otros sectores de la sociedad.

Podríamos pensar que, esta suma de contestaciones implicó el definitivo quiebre de gran parte de la vanguardia plástica porteña con el principal actor institucional modernizador que los había albergado. En los hechos citados podemos encontrar entonces dos formas de abolición del arte: por un lado la que se ejerce desde el Estado autoritario a través de la censura, la persecución judicial y la represión policial. Por otro lado, y como respuesta al régimen de Onganía, cuando los artistas deciden destruir sus obras y arrojarlas a la calle ejercen una acción de violencia contra la materialidad de sus propias obras. Están aboliendo una modalidad artística (en tanto práctica y en tanto ámbito) en la medida en que perciben que hasta ese momento no pudieron evitar que su producción -aún la más crítica y revulsiva- fuera absorbida y neutralizada por las instituciones artísticas. Pero este corrimiento no implicó que renunciaran al arte, sino que muchos de estos jóvenes apostaron a la formulación de un "arte revolucionario", mientras otros emigraron a Europa en búsqueda de condiciones menos hostiles para sus producciones.

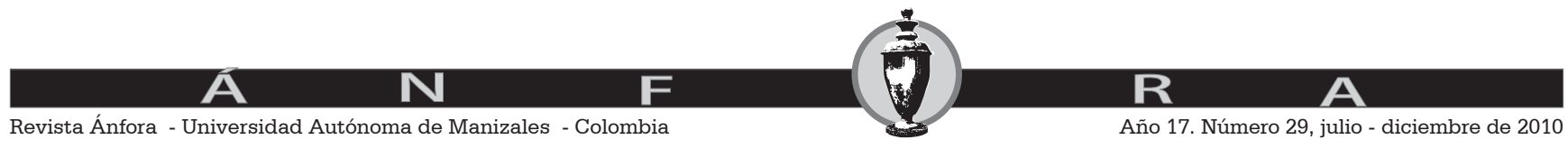


Una nueva acción, esta vez protagonizada por la vanguardia rosarina, sella la ruptura conjunta de los artistas con lo que llamaban "las estructuras de la cultura oficial". El 12 de julio de 1968, Jorge Romero Brest fue interrumpido, mientras daba una conferencia en la sala Amigos del Arte en la ciudad de Rosario. Diez artistas protagonizaron una suerte de "asalto": tomaron la sala, corearon consignas, cortaron las luces y leyeron a oscuras una declaración contra la cultura institucional representada por el Di Tella y a favor de los movimientos populares.

Esta acción violenta en las entrañas de la institución arte adopta como procedimientos artísticos, al igual que las escenas descritas anteriormente, formas de operar propias de las acciones políticas radicalizadas: el sabotaje a un acto público, el apagón, el tono de la proclama manifiesto, la división de tareas en comando, el coro conjunto de las consignas, etc. Poco antes del asalto a la conferencia, a principios de junio, había empezado a gestarse un nuevo eslabón del itinerario, el primero que combinó una acción colectiva de los artistas porteños y rosarinos. Se desencadenó cuando en la convocatoria del Premio Braque 1968, realizada por la embajada francesa, se anexó una hoja suplementaria que modificaba la reglamentación. En ella se obligaba a los artistas invitados a describir sus obras y a "señalar la posible existencia de fotos, leyendas o escritos que las integren". Incluso los organizadores se reservaban el derecho de "efectuar los cambios que juzgaren necesarios" en las mismas. De esta manera poco sutil, la institución pretendía impedir que en el premio se expresara el discurso antiinstitucional que había adoptado la vanguardia.

Su gesto de censura tuvo un efecto boomerang: el nuevo reglamento resultaba inaceptable y la reacción no se hizo esperar. El grupo de Artistas de Vanguardia de Rosario también optó por no participar, e imprimió y repartió un manifiesto, que preanuncia la ruptura con las instituciones artísticas, que se terminaría de concretar pocas semanas después en el asalto a la conferencia de Romero Brest.

El carácter antiinstitucional que progresivamente adoptan las fuentes que analizamos, reflejan la profundización de la ruptura de la vanguardia con las instancias de legitimación de la institución arte, entendidas como aquellas que "ostentan el poder de adjudicar valor artístico" dentro de los límites que la burguesía propone.

En este marco de movilizaciones por la libertad de expresión y de denuncia del estado policial bajo el "onganiato" es que se produce finalmente la inauguración del "Premio Braque", en el Museo de Arte Moderno, el 16 de julio. Durante el discurso de apertura del Embajador francés, se realiza un acto de protesta con manifestaciones, petardos, volanteadas, etc., en contra de la censura y el colonialismo cultural, y se expresa solidaridad con los obreros y estudiantes franceses del movimiento de mayo. La policía interviene, arrestan a 9 artistas y los condenan a 30 días de prisión. La Confederación General del Trabajo (C.G.T. de los Argentinos) ${ }^{7}$ asume la defensa de los detenidos a través de su cuerpo de abogados.
7 Este será el primero de una serie de contactos entre artistas y sindicalistas cuyo punto cúlmine será la Muestra Tucumán Arde.

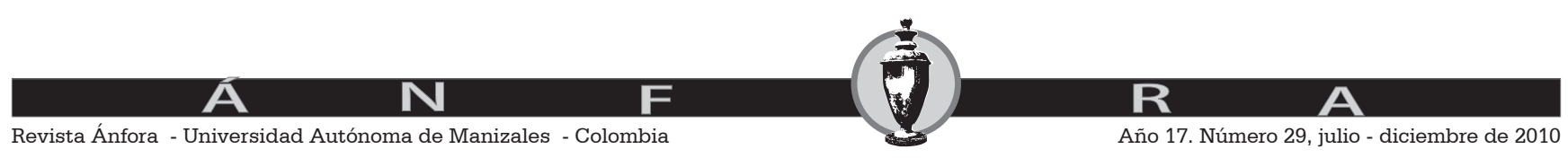


A partir del Ciclo de Arte Experimental se plasma en forma evidente la aceleración de los tiempos políticos en el interior del Grupo de Artistas de Vanguardia. Esto queda demostrado en la necesidad de teorizar sobre su rol como actores sociales comprometidos con la realidad de su tiempo más allá de las especificidades propias del campo artístico del cual, como vimos, se fueron desplazando en forma conflictiva y violenta.

Planificado por el Grupo de Artistas de Vanguardia, a fines de mayo comienza en Rosario el Ciclo de Arte Experimental. Éste estuvo inicialmente auspiciado por el Instituto Di Tella, que les otorgó a los artistas un subsidio para tal fin. Quincenalmente, cada uno de los integrantes del Grupo de Artistas de Vanguardia proponía una experiencia. Si bien El Ciclo se inició en la sala cedida por la agencia de Publicidad de Omar Cuadros luego del asalto a la Conferencia de Romero Brest, cuando los artistas rompen con el Instituto, en un gesto de coherencia ética con sus postulados, devuelven el subsidio y empiezan a autofinanciarse.

El desarrollo del Ciclo que se extiende entre mayo y octubre muestra el acelerado itinerario del grupo: si sus planteos iniciales significaron el abandono de las estructuras primarias para pasar a las ambientaciones y acciones, su culminación marcó el abandono del espacio de la galería, previa ruptura de los vínculos con el Di Tella. Cada una de las experiencias que componen el Ciclo se acompaña con un afiche que anuncia la inauguración, y un volante con un texto del propio artista o citas que se consideran convenientes poner en relación con lo exhibido. El conjunto de estos textos arma un catálogo general del Ciclo. Como presentación inicial, los artistas imprimen un volante en el que aclaran una serie de postulados teóricos que explican el ciclo como parte de un camino recorrido. Los artistas se presentan a sí mismos como "un movimiento orgánico consciente", producto de un recorrido en el que las rupturas escalonadas con las formas tradicionales de hacer arte y la adopción de un método común (lo experimental) dotó de identidad al grupo, superando las individualidades de estilo de cada uno de los artistas.

\section{III}

Una vez fuera de las instituciones artísticas, los artistas se autoconvocan en el I Encuentro Nacional de Arte de Vanguardia realizado en Rosario entre el 10 y el 11 de agosto. Esta instancia colectiva muestra la densidad del proceso de elaboración y discusión de las ideas estéticas y políticas que sustentan el Itinerario del '68, y pone de manifiesto la autoconciencia de los plásticos acerca de la situación límite en la que se encuentran.

La intensidad de las rupturas que venían protagonizando los vanguardistas porteños y rosarinos los instalaba fuera del circuito modernizador. Ese desplazamiento, el abandono de los lugares y los soportes -físicos, materiales, institucionales- conocidos o ya transitados para hacer arte, es vivido por los artistas con una actitud autorreflexiva muy marcada. Esta actitud ya podía percibirse en los escritos -manifiestos, volantes, cartas- con los que acompa-

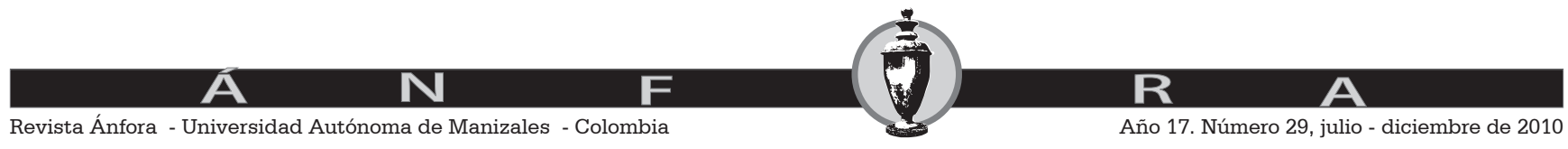


ñan sus intervenciones a lo largo del Itinerario del '68. Pero, sin duda, es el I Encuentro el que congrega al colectivo en un ámbito de discusión y elaboración, al que se suman otros intelectuales.

Como se explicita en el temario de la reunión, el objeto del debate es articular "una teoría que oriente específicamente y aclare el campo de nuestra acción futura" ${ }^{\prime \prime}$. Coinciden en evaluar que las últimas acciones artístico-políticas colocan a sus protagonistas en una posición distinta, nueva, y sin posibilidad de retorno a las instituciones y a la "cultura burguesa". Se proponen como perspectiva la búsqueda de "un nuevo campo", "una nueva función" y "nuevos materiales que realicen esa función", para lograr "una nueva obra que realice en su estructura la conciencia ideológica del artista". Esto es lo que ellos mismos llaman una "nueva estética", que recupera del ideario de las vanguardias históricas la intención de fusionar el arte y la vida, lo que implica concebir un arte inscripto en el proceso que percibían como revolucionario.

El encuentro implicó la ubicación de los artistas en un lugar de producción y elaboración teórica, poco habitual en la plástica. No se agrupan para hacer una obra u organizar una muestra. Se reúnen para evaluar ellos mismos en qué lugar están y hacia dónde deben dirigirse. El punto clave de las discusiones era cuál debía ser el lugar que le correspondería al arte en el proceso político revolucionario. Éstas se polarizaron entre los que proponían no abandonar la experimentación y defendían la importancia de la "búsqueda llamada formal" (citando a Carreira), aún cuando se incorporara la dimensión política; y los que privilegiaban poner la práctica artística al servicio de la intervención política.

Dos de los integrantes, Juan Pablo Renzi y León Ferrari, coinciden en señalar que el carácter revolucionario de la obra no está en la intención subjetiva del creador, ni en el mensaje, sino en la efectividad de la obra en el medio donde se realice y el público al que se dirija. Incluso, la caracterización política de que el triunfo de la revolución es inminente e inevitable, lleva a Renzi a evaluar que, definitivamente rotos los lazos con la cultura burguesa, se abría una etapa de "obras de transición" ya que "un nuevo contexto social cobijará nuestras obras"

Para la vanguardia, en esta nueva etapa se trata de delimitar tanto las formas y medios de acción como las alianzas políticas y las relaciones institucionales. Este punto es crucial para explicar el pasaje de las instituciones modernizadoras (Di Tella) a instituciones ajenas al campo artístico, que ocupan un lugar de oposición al régimen (la CGT de los Argentinos). La defensa de la revolución estética es lo que diferencia a la vanguardia de otras variantes del arte político de ese momento. Todo debe ir a la par de la revolución política. Lo que buscaban era diferenciarse de los artistas vinculados a la izquierda orgánica, ya que consideraban que éstos, al recurrir a contenidos políticos y sociales críticos como "tema", solían ser absorbidos por las instituciones al mantenerse dentro de las galerías, los museos y el mercado de arte.
8 Fuente consultada en el Archivo personal de la artista plástica Graciela Carnevale.

9 Fuente consultada en el Archivo personal de la artista plástica Graciela Carnevale.

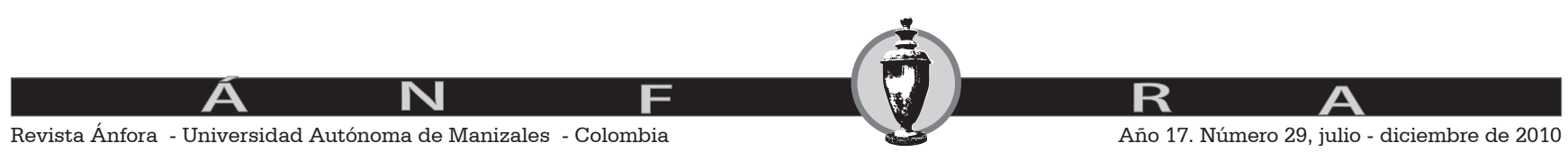


La cuestión de la eficacia de la obra es uno de los grandes nudos del debate: ¿cómo aportar efectivamente desde el arte al proceso revolucionario en marcha? En defensa de la eficacia política y a la vez artística, estos artistas se pronuncian por mantenerse en el terreno del arte: defienden sus acciones como arte de vanguardia y a sí mismos como artistas de la "verdadera vanguardia" en contraposición a la falsa vanguardia formalista y despolitizada.

Algunos integrantes del grupo como Nicolás Rosa, Juan Pablo Renzi y León Ferrari remarcan las posibilidades de los usos de los medios masivos en el arte, remitiéndose a las nuevas teorías de la comunicación. Estas concepciones están claramente presentes en la planificación y realización de "TUCUMÁN ARDE", cuya pretensión central será generar un circuito contrainformacional que desmintiera la propaganda oficial.

Pensamos el Encuentro como un preámbulo de "TUCUMÁN ARDE”, ya que en éste se reafirmó la voluntad de los artistas de confluir en una realización colectiva y se enunciaron en forma teórica algunos de sus rasgos. En Buenos Aires, en un segundo encuentro se aprueba la realización de una primera obra colectiva que consistirá en la realización de una campaña de agitación acerca de la situación que afecta al pueblo tucumano y la incorporación de la CGT de los Argentinos en forma de comisión.

\section{IV}

A través de su programa fundacional, el $1^{\circ}$ de mayo de 1968 y tomando a Tucumán como paradigma de la crisis que atravesaba el país, la CGT de los Argentinos hizo un llamamiento que involucró a sectores del capital nacional y a otros sectores de la sociedad, logrando un triunfo muy importante en el establecimiento de un vínculo con los estudiantes y con un grupo de artistas e intelectuales locales (VIANO, 2000). En sus tres o cuatro años de existencia efectiva, la CGT de los Argentinos intentó en su práctica cotidiana ser un ámbito de convergencia. Lo consiguió, de manera parcial, incompleta, a veces conflictiva, en el plano de la relación entre organizaciones sindicales y políticas del peronismo revolucionario, la izquierda y la Iglesia tercermundista. También en el del encuentro en la acción entre ese activismo y grupos de intelectuales, profesionales y artistas.

En el I Encuentro Nacional del Arte de Vanguardia surgió la idea de trabajar sobre la base del plan de lucha de la CGT de los Argentinos, ya que había varios intelectuales trabajando ahí. Nos parece importante destacar que este trabajo en conjunto no implicó el alineamiento de los artistas con este movimiento político, sólo era una confluencia de intereses: el profundo desacuerdo con el conjunto de políticas aplicadas por el gobierno de facto del Gral. Onganía y desenmascarar así la propaganda oficial para que el pueblo entero conozca la real situación de pobreza y exclusión que atravesaban las regiones del país.

La central obrera se involucró mucho con el proyecto de los artistas, principalmente se encargó de establecer los lazos necesarios entre los artistas

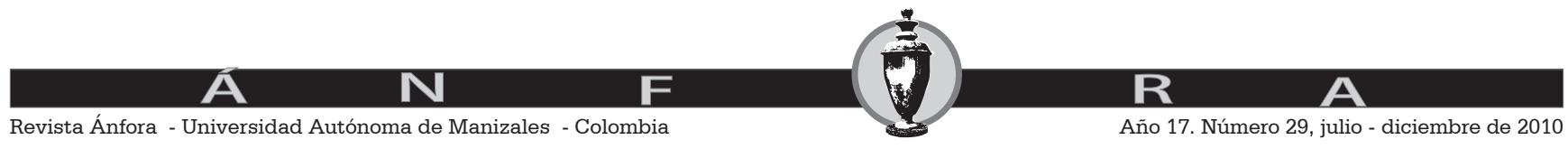


y los obreros tucumanos. La circular que envió la CGT de los Argentinos a todos los gremios del país es un ejemplo del compromiso que ésta asumió con la actividad de los artistas. En la misma se hace pública y explícita la "concordancia con el plan de acción" ante todas las secretarías gremiales y la colaboración entre la Comisión de Cultura de la CGT de los Argentinos y el Grupo de Artistas de Vanguardia.

Esta colaboración entre la central obrera y los artistas es inédita y no volverá a producirse. Pero mientras duró fue muy efectiva y se fortalecieron lazos de solidaridad que permitieron que la muestra "TUCUMÁN ARDE" pudiera ser expuesta en la ciudad de Rosario en la sede de la central obrera.

\section{V}

El conjunto de políticas diseñadas por el Estado Nacional, conocidas como "Operativo Tucumán", tenía como objetivo declarado la racionalización y diversificación de la industria local. Este programa implicaba una forzada retracción de la producción azucarera. Con el fin de llevar adelante estas políticas, se montó una fuerte y masiva propaganda oficial. Para ello el gobierno se valió de una campaña publicitando en los medios masivos de comunicación las ventajas y virtudes del rumbo de la economía. Pero todo era ficticio, ya que la realidad que vivía la provincia de Tucumán, como lo van a demostrar los artistas, era otra.

Lo que se proponen entonces es hacer una muestra/denuncia sobre la situación de Tucumán. "Tomamos un elemento socio-político del momento y lo llevamos al arte" nos dirá Jaime Rippa, uno de sus integrantes. Para hacer efectiva la denuncia organizaron un plan de acción y se valieron de trabajos interdisciplinarios. Como sabemos, el grupo de artistas venía teniendo reuniones y trabajando en forma conjunta con sociólogos, escritores y sindicalistas.

La realización de la obra "TUCUMÁN ARDE" por el Grupo de Artistas de Vanguardia comprendió cuatro etapas: la primera de recopilación y estudio del material documental; una segunda etapa de verificación y confrontación de la realidad tucumana a través del trabajo de campo en dicha provincia y un paralelo programa de propaganda en la ciudad de Rosario; una tercera etapa de realización de las muestras en Rosario y Buenos Aires; por último la cuarta etapa que consistía en el cierre del circuito sobreinformacional acerca del problema tucumano. Éstas muestran la magnitud del proyecto y el compromiso asumido por los artistas

Comoveremos, esteplansecumplióhastalaterceraetapa,cuandoellevantamiento abruptodelamuestraenBuenos Airesinterrumpióeldesarrollodelaobra. Quedaron en suspenso dos obras planificadas (en Santa Fe y Córdoba) y la $4^{\mathrm{a}}$ etapa.

VI

Una vez recopilados todos los datos necesarios, la obra se montó en el local

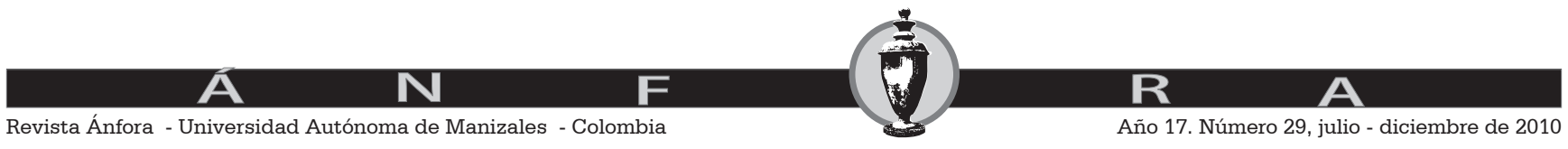


de la CGT de los Argentinos de la ciudad de Rosario. Como vimos, previamente se había realizado una campaña publicitando la "Primera Bienal de Arte de Vanguardia" con el fin de generar una gran expectativa y atraer espectadores. El 3 de noviembre se inauguró la muestra con una gran asistencia de público. Al ingresar al local de la CGT de los Argentinos se les entregaba a los visitantes un volante donde se encontraban explicitados los lineamientos que tenía la obra, su fuerte contenido de denuncia y sus aspiraciones de provocar un fuerte impacto en el público.

La idea no era arrinconar la muestra en un par de salas, restringirla a una zona acotada que pudiera visitarse a la manera de las exposiciones de arte tradicionales, sino "ocupar" el edificio. Esta idea de "ocupación" o "toma" de la CGT implicó aprovechar todos sus espacios y posibilidades para integrar e intervenir incluso en la rutina del sindicato. Así podrían pensarse las muestras de "TUCUMÁN ARDE", como la puesta en juego de un modo en que el arte se instala en/ se apropia de/ se confunde con un espacio público, alternativo a los circuitos artísticos (LONGONI y MESTMAN, 2000).

El público deja así de estar frente a la obra para situarse en la obra, penetrándola, moviéndose dentro de ella. El conjunto del montaje apuntaba así, a impactar en el espectador a través de todos los sentidos, al presentarse como un "bombardeo" de información visual, escrita, sonora y hasta gustativa. Una denuncia construida a partir de una combinación del muestrario de imágenes y datos contundentes con una explicación científica (desde el paradigma sociológico) de sus causas y consecuencias, sus beneficiarios y sus cómplices.

En relación a las colaboraciones entre porteños y rosarinos a la hora de montar las muestras, los artistas habían llegado a un acuerdo de hecho: cada grupo se manejaba con cierta autonomía y se responsabilizaba del montaje de la muestra de su ciudad. En Buenos Aires, la muestra en la sede central de la CGT de los Argentinos se inauguró el 25 de noviembre y debía continuar hasta el 30 de ese mes. En el acto de inauguración Raimundo Ongaro, Secretario General de la CGT de los Argentinos, se dirigió a los asistentes destacando el aporte de los artistas a la difusión de la lucha de los trabajadores. Pocas horas después de la inauguración, ante las presiones de funcionarios de la dictadura, la muestra fue levantada.

Las versiones de los artistas sobre la inmediata clausura coinciden con la explicación sindical: el levantamiento se decide de común acuerdo entre sindicalistas y artistas, ante la amenaza del gobierno de intervenir la central obrera, quitarle la personería jurídica o clausurar el local sindical. Se repetía una vez más, una modalidad de intervención del poder político sobre la esfera cultural tan frecuente en esos días: la censura, persecución o clausura inmediatas de cualquier hecho, muestra, espectáculo que planteará críticas al régimen. Podemos considerar el cierre judicial de la muestra como el momento de mayor eficacia, ya que esto prueba que el mensaje de la vanguardia era inadmisible para las instituciones oficiales.

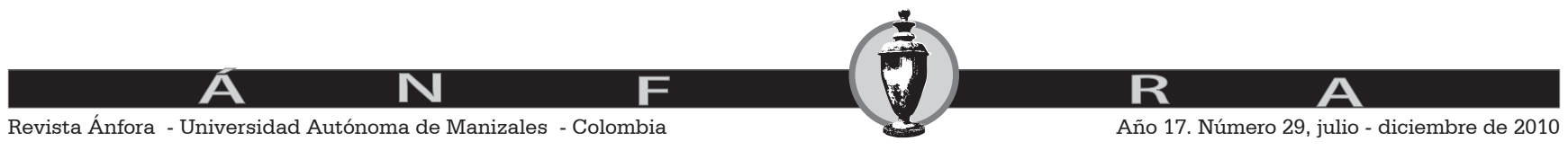


Los artistas se habían propuesto "estar ligados a grupos sociales con suficiente poder como para que sus mensajes culturales sean escuchados", lo que se concreta al articular el arte de vanguardia con la CGT de los Argentinos. Sin embargo, la clausura de la muestra en Buenos Aires evidenció los límites de esa relación y los llevó a barajar otra alternativa. De esta forma se había evidenciado la fragilidad del soporte institucional que ofrecía la CGT de los Argentinos frente a la represión del régimen, por lo que los artistas optaron por no realizar las muestras programadas en Santa Fe y en Córdoba. Tampoco se continuó con el plan de recopilación, análisis y publicación de los materiales que componía las muestras. Los materiales recopilados retornaron a Rosario, y en los años siguientes se fueron dispersando.

La principal tarea política de los artistas de vanguardia era la subversión del marco institucional. Al comprobar con impotencia la capacidad que éste demostraba para neutralizar los desafíos más extremos, los artistas deciden abandonar el arte llevando así al límite la radicalización artística. Los artistas se comprometieron a no participar en galerías, museos, premios, becas, ni ningún otro espacio institucional del arte de la burguesía. Cumplieron esa suerte de juramento a rajatabla, ya que ninguno de ellos retorno, al ámbito de las artes plásticas en los años inmediatos.

¿Qué falló? Consideramos como una posible respuesta a este interrogante que la alianza Grupo de Artistas de Vanguardia - CGT de los Argentinos era más débil de lo que se imaginaban los artistas. La CGT de los Argentinos no estaba dispuesta a poner en riesgo su propia existencia como tal por albergar a la muestra.

\section{CONCLUSIÓN}

Vemos como en el devenir del itinerario del '68 y ante la aceleración de los tiempos políticos se produce la apropiación artística de discursos, formas, modos, estilos y procedimientos propios de la vanguardia política. Es decir, las prácticas "militantes" (volantes, pintadas, actos-relámpagos, sabotajes, secuestros, acciones clandestinas) son recuperadas, recreadas por estos artistas en sus acciones, producciones y discursos. De esta forma los artistas sellan el pasaje de las instituciones artísticas oficiales de consagración, a instituciones políticas opositoras al régimen de Ongania.

Este desplazamiento de la vanguardia artística hacia una institución políticosindical de oposición, necesariamente impuso nuevas reglas de juego, otras formas de negociación y circulación de la obra. La vinculación sindical, así como la autoría colectiva y los esfuerzos por llegar a un nuevo público (masivo y popular) y por encontrar un nuevo lenguaje dan cuenta del camino de redefinición del vínculo arte-vida-política en el que está inmersa la vanguardia.

Conforme la nueva estética que postulan estos jóvenes de vanguardia, el arte debe aportar eficazmente a la transformación social y no limitarse a ser un mediador, un soporte, un instrumento político. En este sentido no basta con

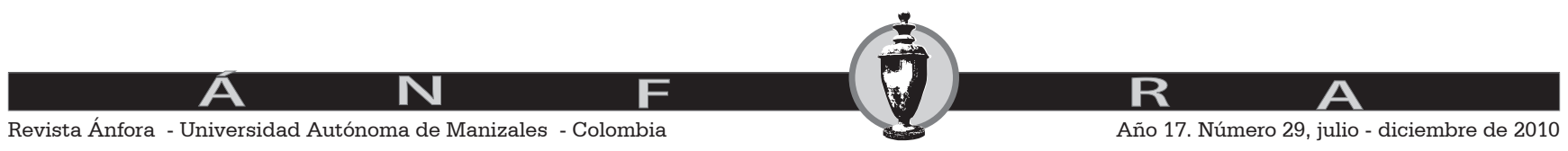


la adhesión personal del artista a determinada causa, ni siquiera con su militancia, sino que es necesaria la producción de una obra de arte objetivamente revolucionaria, que realice en sí misma la voluntad de cambio (político y estético) de su creador. La revolución artística debe ir a la par de la revolución política.

Esta transformación es una acción colectiva, que incluye al grupo de artistas de vanguardia, (que no es un colectivo homogéneo ni desde el campo cultural ni desde el político) a la CGT de los Argentinos y al público, especialmente estudiantes y obreros. En "TUCUMÁN ARDE", tanto la intervención en los medios, como el lugar que ocupó el documentalismo en las muestras y el recurso a códigos convencionales (políticos, periodísticos, publicitarios) se asociaban a la eficacia en la comunicación que se pretendía entablar con ese nuevo público. La articulación de los elementos en la obra en pos de un objetivo contrainformacional dan cuenta de un hecho artístico realmente novedoso.

La muestra "TUCUMÁN ARDE" sólo fue posible gracias a la apreciación cabal de los artistas sobre el momento histórico que estaban viviendo. Como vimos en la muestra, confluyeron el conocimiento científico de la realidad social junto al conocimiento de las ciencias de la comunicación, disciplinas pertenecientes al arte y mecanismos propios del ámbito político. Estas experiencias son irrepetibles, también lo son las circunstancias históricas que las provocan, aunque no mecánicamente. "TUCUMÁN ARDE" fue un arte revolucionario en un contexto revolucionario.

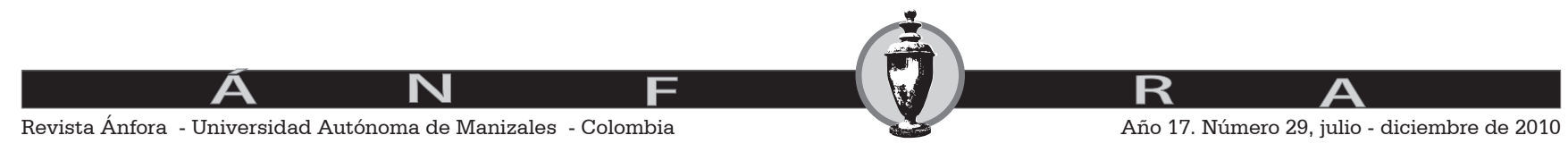




\section{Bibliografía}

ALTAMIRANO, C. y SARLO, B. (1983). Literatura y Sociedad. Bs. As.: Hachette.

ANGUITA, E., CAPARRÓS, M. (2007). La voluntad. Una historia de la militancia revolucionaria argentina. (Tomo I 1966-1969). Bs. As.: Booket.

BALBE, B. (2001) ¿La fusión del arte y la política o su ruptura? El caso de Tucumán Arde: Argentina 1968. Investigaciones. Razón y Revolución. (Nº 7 )

BOURDIEU, P. (1983). Campo del poder y campo intelectual. Bs. As.: Folios Ediciones.

FANTONI, G. (1988). Horizontes problemáticos de una vanguardia de los años sesenta. Un movimiento entre el heroísmo y la crisis. Anuario. Segunda época, UNR, FHyA, Escuela de Historia. ( $\left.N^{\circ} 13\right)$. Rosario: UNR Editora.

FANTONI, G. (1989-1990). El impacto de lo nuevo en los primeros sesenta. Conformación y emergencia de un grupo de vanguardia. Anuario. Segunda época UNR, FHyA, Escuela de Historia. (N 14). Rosario: UNR Editora.

FANTONI. G. (1994). Tres visiones sobre el arte crítico de los años sesenta. Conversaciones con Pablo Suárez, Roberto Jacoby y Margarita Paksa. Documentos de trabajo. Vol. I.

FANTONI, G. (1998). Arte, vanguardia y política en los años '60. Conversaciones con Juan Pablo Renzi. Bs. As.: El cielo por asalto.

GARCÍA CANCLINI, N. (2005). La Producción Simbólica. Teoría y método en sociología del arte. México: Siglo XXI.

GARCÍA CANCLINI, N. Los jóvenes no se ven como el futuro: ¿serán el presente? Recuperado el 28 de Mayo de 2009. http://www.pensamientoiberoAméricano.org.

GIUNTA, A. (2001). Vanguardia, internacionalismo y política. Arte argentino en los años sesenta. Bs. As.: Paidos.

GORELIK, A. (2005) Preguntas sobre la eficacia en Punto de Vista. (Nº 82).

JAMES, D. (2006). Resistencia e integración. El peronismo y la clase trabajadora argentina, 1946-1976. Bs. As.: Siglo XXI.

LONGONI, A. y MESTMAN, M. (2000). Del Di Tella a "TUCUMÁN ARDE". Vanguardia artística y política en el '68 argentino. Bs. As.: El Cielo por Asalto

OLIVERAS, E. (2006). Estética. La cuestión del arte. Bs. As.: Ariel.

PLÁ, A. (Coord) (2000) Rosario en la Historia (de 1930 a nuestros días) Tomo II, Rosario: UNR Editora.

RAMÍREZ, A. (2008). “Tucumán 1965-1969: movimiento azucarero y radicalización política". Recuperado el 25 de noviembre de 2008, de http://nuevomundo.revues.org/ index38892.html.

ROMERO, J. L. (2005). Las ideas políticas en Argentina. Bs. As.: Fondo de Cultura Económica.

SIGAL, S. (1991) Intelectuales y poder en la década del sesenta. Bs. As.: Puntosur

SOUTO KUSTRIN, S. (2007) "Juventud, teoría e historia: la formación de un sujeto social y de un objeto de análisis." Recuperado el 28 de mayo de 2009, de http://dialnet.unirioja. es.

TERÁN, O. (1991).Nuestros años sesenta. La formación de la nueva izquierda intelectual en la Argentina 1956-1966. Bs. As.: Puntosur.

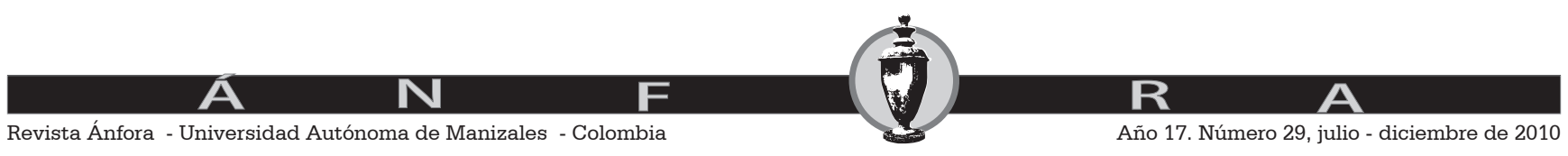

